\title{
The Implications of a Narrow Understanding of Gender-Based Violence
}

\author{
Karen Graaff ${ }^{1 *}$
}

Published: March 5, 2021

\begin{abstract}
Gender-based violence (GBV) has increasingly been recognised as a global issue. While initially focused primarily on men's violence against women (VAW), in response to extremely high rates of VAW globally, the definitions of GBV used by different governments and organisations have expanded to include violence against the LGBTQIA+ community, and sometimes violence against men. However, in practice, many organisations still apply narrow understandings of VAW. This article argues that the exclusive focus on VAW in GBV prevention efforts may in fact hinder their effectiveness, by excluding many groups who also experience GBV, often at higher rates than the cis-gendered women who are traditionally seen as its victims or survivors. ${ }^{1}$ Thus, a narrow focus on VAW may result in the exclusion of violence against those in the LGBTQIA+ community from interventions, support, and legal and other protective mechanisms. Similarly, it may result in the exclusion of violence against and between men, despite the overwhelming societal heteropatriarchal pressure on them to enact and receive violence. With a particular focus on South Africa as a case study, this article posits that failing to address the full range of gendered violence may result in a failure to effectively address GBV at all.
\end{abstract}

Keywords: GBV, LGBTQIA+, masculinities, intersectional identities, South Africa

\section{INTRODUCTION}

Gender-based violence (GBV) is increasingly being recognised as a serious issue worldwide. As a result, a slew of legislation, policies, and intervention efforts have been implemented to try and address it. However, despite the development of increasingly inclusive definitions of GBV, this article argues that, in reality, the focus remains almost exclusively on men's violence against women (VAW) as the only recognised form of GBV. ${ }^{2}$ South Africa is no exception. It is a country with relatively progressive and inclusive legislation: it has legalised gay and lesbian marriage, it allows transgender people to change their gender on their identity document, and it has a very broad and inclusive definition of rape and sexual violence, all of which will be discussed in more detail below. However, it is also a country with extremely high rates of all forms of violence, and particularly gender-based violence, as will also be outlined below. Thus, it is a context where efforts to effectively address all forms of GBV are arguably more urgent than others. However, the public discourse remains predominantly focused on VAW which, important though that is, excludes and others widespread forms of violence against minority communities.

The narrow focus on VAW in GBV intervention efforts results in the exclusion of violence against gender nonconforming (GNC) individuals, as well as others in the lesbian, gay, trans, queer, intersex, asexual (LGBTQIA+)

\footnotetext{
${ }_{1}^{1}$ There is some debate about the best term to use for those who have experienced GBV (see Thompson, 2000), with some preferring the term 'victim', others using 'survivor', and others perhaps preferring a different term altogether. There is insufficient space here to discuss the debate in detail, but I have attempted to use the term 'survivor' throughout, to highlight their agency in processing and managing their experience of violence. However, I acknowledge that this may not be applicable to all those who have experienced GBV.

2 This article predominantly focuses on sexual violence and IPV when discussing GBV, largely because these are the forms of violence most commonly discussed in literature on the issue. However, the author acknowledges the very wide range of acts falling within this category of violence, as well as the lack of research and literature on such acts. These include verbal harassment, physical attacks by strangers, denial of access to health and education services (Dolan, 2014), legislated inequality, homelessness or being denied shelter (James et al., 2016), and lack of access to legal redress or justice (Crehan and McClearySills, 2015).
} 
community, and violence between men. A narrow application of the concept of GBV in prevention efforts may fail to address the full range of gendered violence, and therefore only be successful in preventing heteronormative and cis-gendered forms of GBV. This article argues that the applied definition of GBV should be expanded to be more inclusive, in order to effectively address the scourge of gendered violence in a matrix of gendered contexts, and gender inequality more broadly. It draws on existing literature to highlight the limitations of current understandings of GBV in practical interventions, as well as providing some examples of ways in which this can impact and harm groups in society in practice. The article begins with an overview of the development of increasingly inclusive definitions of GBV globally, before focusing in more depth on South Africa. The article then turns to the ways that intervention efforts apply the stated definitions of GBV, as well as outlining the implications that this may have in terms of efforts to end GBV.

\section{DEFINITIONS}

Initial policies to address GBV focused almost entirely on VAW, in order to highlight the likelihood of violence that many women and girls experience daily. Similarly, feminists and gender activists have long focused on VAW, to emphasise that it is specifically targeted at women, because they are women living in gender-unequal societies. The fact of women working, wearing short skirts, drinking alcohol, or being out of the home unsupervised is not what causes the violence, as suggested by recalcitrant rape myths. Rather, women's position in society, notwithstanding complex intersections with other forms of inequality, is what makes them more vulnerable to certain forms of violence, and is therefore a systemic issue which needs to be addressed at a systemic level, rather than suggesting that individual women need to simply change their behaviour in order to prevent violence. There are therefore strong reasons for organisations to focus on VAW as a priority.

While the original text of CEDAW (Convention on the Elimination of all forms of Discrimination Against Women) did not specifically mention GBV, the CEDAW Committee's General Recommendation 19 (1992) defined GBV as 'violence that is directed against a woman because she is a woman or that affects women disproportionately' (para. 6). This was underlined in General Recommendation 35 (2017), which used the term 'gender-based violence against women' throughout. Similarly, the Council of Europe Convention on preventing and combating violence against women and domestic violence (known as the Istanbul Convention, which came into force in 2014), and highlighted by the European Institute for Gender Equality (EIGE) as 'the benchmark for international legislation on tackling gender-based violence', focuses on 'gender-based violence against women' (EIGE, n.d.).

Some organisations specifically state that they use GBV and VAW interchangeably because the majority of victims are women and girls (EIGE, n.d.; Dolan, 2014). Many highlight the fact that gender inequality is so pervasive worldwide that women in all countries experience discrimination and violence because of their gender, and thus make up the majority of the survivors of GBV (IASC, 2015). It is true that women and girls bear a heavy burden of violence. Globally, it is estimated that $35 \%$ of women have experienced either physical and/or sexual intimate partner violence (IPV) or sexual violence by a non-partner at some point in their lives (WHO, 2013). Along with this, more than a third of the women intentionally killed in 2017 were killed by their current or former intimate partner (UNODC, 2019).

However, increasingly there have been moves to broaden the definition of GBV to include all those who experience violence based on their gender. For example, in their fact sheet on homophobic and transphobic violence, the United Nations Office for the High Commissioner for Human Rights (UN OHCHR) notes that, '[a]ttacks on people because of their sexual orientation or gender identity are often driven by a desire to punish those seen as defying gender norms and are considered a form of gender-based violence' (n.d.: 1). Similarly, the Caribbean and Vulnerable Communities Coalition (CVC) and UNWomen note, 'GBV usually occurs when one does not meet stereotypical gender expectations, as well as when one is in a relationship with uneven power dynamics' (2016: 6-7). Further, 'gender based violence is rooted in structural inequalities based on gender norms that value men over women, masculinity over femininity, and heterosexuality over homosexuality and cisgender people over trans people' (2016: 7).

According to UNWomen (2013), the definition of GBV that is currently most commonly referenced in humanitarian settings is that adopted by the UN Inter-Agency Standing Committee (IASC) GBV Guidelines, which defines GBV as 'an umbrella term for any harmful act that is perpetrated against a person's will, and that is based on socially ascribed (gender) differences between males and females' (IASC, 2015). This definition therefore includes violence against GNC individuals, as well as others in the LGBTQIA+ community, and violence between and against men and boys which is based on societal expectations of masculinities which encourage or enable violence by and against men. Organisational definitions of GBV have therefore become relatively more inclusive over time. The following section focuses on the situation in South Africa. 


\section{SOUTH AFRICA AND GBV}

South Africa is a country which is heavily impacted by VAW, and by GBV more broadly. Based on statistics from previous years, more than 50000 women are likely to be raped in the country this year (UNODC, n.d.), and a woman will be killed by her intimate partner every six hours, the highest rate ever recorded in the world (Mathews et al., 2004). In 2012, GenderLinks and the Medical Research Council (two South African NGOs) conducted a survey on the prevalence of VAW in four provinces (Gauteng, Western Cape, KwaZulu-Natal, and Limpopo). Between one third and three quarters of women in all four provinces reported experiencing some form of violence at least once in their lifetime, with Limpopo (77\%) reporting the highest rates, followed by $51 \%$ in Gauteng, $45 \%$ in the Western Cape, and 36\% in KwaZulu-Natal. In addition to this, men were asked whether they had ever committed some form of VAW. The numbers ranged from 35\% in the Western Cape, to $41 \%$ in KwaZulu-Natal, 48\% in Limpopo, and as high as 78\% in Gauteng. As noted by the authors (2012: 6), the study 'confirms the disturbingly high prevalence of violence against women in South Africa'. An earlier study by Jewkes et al. (2009) found that $27.6 \%$ of South African men reported having raped a woman, and of those, $46.3 \%$ had raped more than once.

Certainly, the country's history, and current postcolonial and post-apartheid context play a role in these extremely high rates of violence (Breckenridge, 1998; Anderson, 1999/2000). Numerous authors have highlighted how the system of apartheid ${ }^{3}$ may have normalised extreme levels of violence (Morrell, 1998; Hamber, 2000). Along with this, both the apartheid state and the liberation groups struggling against apartheid were often characterised by gender inequality and violence, with little effort being made to achieve gender equality, as 'gender was relatively unimportant in the context of race oppression' (Morrell et al., 2012: 19). Potentially as a result of this, numerous writers have noted that South Africa displays a rape culture (Gqola, 2015), which normalises, condones, excuses, encourages or ignores rape (Flintoff, 2001), and which facilitates 'continued tolerance of aggression toward women, and thus the occurrence of sexual violence' (Aosved and Long, 2006: 481). Thus, South Africa is a context where it is arguably of even greater importance to address GBV as effectively as possible, given the extremely heavy burden that it places on the country.

Given this, it is perhaps surprising that South Africa's legislation around GBV is relatively progressive and encompassing. For example, the Criminal Law (Sexual Offences and Related Matters) Amendment Act declared that all forms of sexual penetration without consent, irrespective of gender, are considered rape; and the country officially recognised rape within a marriage as a crime in 1993. Along with this, the Domestic Violence Act includes same-sex couples under their definition of a domestic relationship. Despite this, official policy documents in the country have still tended to conflate VAW with GBV, such as in the White Paper on Safety and Security (2016), which only mentions GBV under the heading of 'Violence Against Women'. Along with this, the South African government's response to GBV has typically fallen under the Department of Women, Youth and Persons with Disabilities, rather than the Department of Justice, implying a narrower focus on VAW, rather than GBV more broadly. However, a recent draft of the National Strategic Plan (NSP) on GBV and Femicide advocates for a broader and more inclusive definition of GBV, which is worth quoting at length:

Current rhetoric around GBV is mostly focused on violence experienced by ciswomxn (womxn whose gender identity and sex at birth matches). LGBTQIA++ individuals may also experience GBV, particularly in contexts when this violence is targeted at someone on the basis of their gender identity or sexual orientation or being gender non-conforming and/or not practicing heterosexuality. Violence may also be used to feminize men, or undermine their masculinity, ensuring that they are not exempt from some forms of GBV (2019: 13).

The government's development of an NSP for GBV was partly in response to consistent pressure from the Stop Gender Violence Campaign. ${ }^{4}$ The campaign published their own draft NSP in 2014, and in a 2017 policy brief, their first listed strategic priority was to expand the definition of GBV, noting that it should include all forms of harm perpetrated against 'women, girls, men, boys, LGBTI person and other vulnerable groups (such as sex workers, refugees, prisoners, and HIV-positive people)' (2017: 2). Thus, South African legislation and civil society policies are relatively broad and inclusive in their definition of GBV.

\footnotetext{
${ }^{3}$ Apartheid was the racially discriminatory system in South Africa which was legally enforced from 1948 until the early 1990 s. The population was divided into four racial groups (white, black, Indian, and 'coloured'), and given separate education, employment, public amenities, living areas, and civil and human rights, with white people prioritised.

${ }^{4}$ The Stop Gender Violence Campaign is made up of a group of South African civil society organisations which campaigned over a number of years to pressure the SA government to adopt an NSP to address GBV. For more information, see NSPGBV Campaign on Facebook.
}

(C) 2021 by Author/s 


\section{APPLICATION}

Despite increasing inclusivity in governmental and organisational definitions of GBV, in practice GBV is still mostly taken to mean solely VAW, and specifically sexual and domestic violence against women. This may mean that many of the interventions and protections designed to address and prevent GBV and provide support to survivors may be exclusionary. The first way this could arise is in legal terms, where the definitions that countries use of gender, sexual violence, and rape will impact on what acts are criminalised, and what legal protection is available. For example, while globally there has been a gradual broadening of rape definitions to use more genderneutral terms, some countries maintain predominantly heteronormative definitions. Along with this, numerous countries still criminalise same-sex relationships and intercourse. On the African continent, the majority of countries criminalise same-sex sexual activity, often imposing prison terms, fines, or even the death penalty (such as in Nigeria, Mauritania, and Somalia), meaning that a survivor of same-sex rape will not be able to report it for fear that they will be arrested, imprisoned or even killed themselves (Kiss et al., 2020: 12). These cases would therefore be excluded from both local and global GBV statistics. Similarly, if countries do not recognise transgender persons' identities, or even criminalise them, then they will feel unable to report GBV, as they may face legal repercussions or even violence from the police (James et al., 2016).

Along with this, organisations working on GBV may still in practice focus on VAW, despite their own commitment to a broader definition of GBV. For example, one South African NGO (Sonke Gender Justice), which was one of the initial members in the Stop Gender Violence Campaign, and which works extensively with men to prevent GBV, notes on their website the activities undertaken by the Campaign. A primary action was a postcard campaign 'with individualised personal stories of women affected by GBV, which are posted to the Minister of Women' (Sonke Gender Justice, n.d.). Despite the campaign's stated strategic priority of expanding the definition of GBV, there are no corresponding postcard campaigns for LGBTQIA+ survivors, or for male survivors.

The narrow working definition of GBV also limits access to support and protection for survivors who do not fit the 'men's-violence-against-women' definition. For example, a common means to provide support to survivors of domestic violence are residential shelters (Ellsberg et al., 2015). Because of the above-mentioned high rates of IPV against women by men, many residential shelters are women-only, meaning that a male perpetrator will not be able to enter the shelter, and female survivors have some semblance of safety. However, this can exclude male survivors of IPV, for whom there are substantially fewer shelters available. Similarly, shelters may well exclude trans women, especially in countries where trans rights and identities are not recognised. Along with this, such shelters will be less helpful for survivors of female violence, such as women in abusive same-sex relationships, as their female abuser will also be able to enter the shelter (Naidu and Mkhize, 2005; Brown and Herman, 2015).

Focusing exclusively on VAW also means that many interventions intended to prevent and reduce GBV may exclude or ignore violence against the LGBTQIA+ community, and violence against men. Thus, even if such interventions are able to limit some specific forms of VAW, they may not succeed in addressing GBV and gender inequality more broadly. For example, masculinities-focused interventions are increasingly being implemented as a form of GBV prevention in numerous sites around the world, including in South Africa. Such programmes work predominantly with men, acknowledging that the vast majority of violent crime and GBV is perpetrated by men. As Jewkes, Flood and Lang note, these interventions are 'motivated by a desire to address the role of men in violence perpetration, and recognition that masculinity and gender-related social norms are implicated in violence' (2015:1580). These have shown some promise, with participants self-reporting improvements in relationships with partners and children, their use of violence, and safe sex practices (Pulerwitz et al., 2004; Bhandari, 2008; TravesKagan et al., 2020).

However, studies have shown that the implementing organisations generally maintain a narrow focus on VAW, rather than GBV more broadly. For example, Sonke Gender Justice, a South African NGO mentioned in the discussion of the Stop Gender Violence Campaign above, implements masculinities-focused interventions, which have been studied and evaluated by numerous authors, noted in this paragraph. Despite the organisation's stated broader definition of GBV, studies found that the interventions maintained a narrower VAW focus, with the result that participants are less likely to view violence against the LGBTQIA+ community as a form of GBV (Viitanen and Colvin, 2015; Graaff and Heinecken, 2017), and consequently do not necessarily see it as problematic. Similarly, there is little attention paid to violence against men, despite recognition within the interventions that men's use of violence is heavily gendered, and often expected of them because of dominant 'toxic' masculinities in their communities (Fleming et al. 2015). This is despite the fact that, 'there is substantial evidence that perpetrators of one type of physical violence are more likely to perpetrate other types of violence' (Fleming et al. 2015: 251). Thus, focusing on only one form of violence may result in interventions that do not effectively address any forms of GBV. This seems to be borne out by numerous recent studies. For example, Gibbs et al. (2020: 548) found that such interventions may result in only small positive changes in men's use of violence, while Christofides et al. 
(2020) and Traves-Kagan et al. (2020) found no effect on participants' use of physical or sexual IPV and nonpartner rape.

\section{IMPLICATIONS}

The following section outlines the reasons why the application of a narrow understanding of GBV is problematic. The first is that it risks implying that all women are at equal risk of violence, which ignores the multiple intersecting social identities that increase a woman's risk of GBV. Secondly, it may serve to exclude awareness of and attention to violence against and among those in the LGBTQIA+ community, as well as the numerous gendered forms of violence both between and against men. This section is broken up into those in the LGB community, those in the TQIA+ community, and men. However, it is important to note that there may be numerous overlaps between these identities.

\section{Women as a Homogenous Group}

A primary issue arising from the conflation of VAW with GBV is its focus on relatively traditional gender roles and gender binaries, predominantly focusing on (cisgender and heterosexual, or cis-het) men's violence against (cis-het) women, and portraying 'woman' as a monolithic identity, with the implication that all women are exposed to equal risk and experience of violence. This obscures the many intersecting identities which may overlap with a person's identity as a woman, and may hide or ignore how these can impact their risk of GBV. A woman's overlapping socio-cultural identities (such as being a Black woman, or a queer disabled woman, or a trans woman, or a migrant woman) will expose them to increased levels and risk of violence, as they are 'punished' both for being a woman, and for transgressing other societal norms or for being a member of marginal, othered communities. ${ }^{5}$ However, few studies 'employ an intersectional lens to recognize the multifaceted confluence of race, gender, class, and sexual orientation as unique risk factors for extreme violence' (Clark, Mays and Cochran, 2017: 2), which ignores how 'gender-based violence may affect some women to different degrees, or in different ways' (CEDAW, 2017: 5).

Some studies have highlighted the varying identities that may result in increased risk for women. For example, a 2018 study found that women with disabilities in low and middle-income countries experience two to four times the rate of IPV as non-disabled women (Dunkle et al., 2018). This may suggest that their societal precarity as a result of having a disability, and particularly the likelihood of their being dependent on a person who may also be their abuser, exacerbates their risk of violence. Thus, they are targeted not only because they are women, but also because they are women with disabilities. In a similar fashion, studies consistently show that women who are sex workers experience significantly higher rates of violence than women who are not sex workers, including exploitation, harassment, and physical and sexual violence, from managers, clients and police officers (CVC/UNWomen, 2016: 14; James et al., 2016; Evens et al., 2019). This may well be linked to their societal and legal precarity, especially in countries such as South Africa where sex work is still criminalised. As noted by CVC and UNWomen (2016: 13), female sex workers are put in a 'precarious situation when male clients use violence against them and refuse to practice safe sex', as there is limited legal protection for them. Thus, they are targeted for being women and for being in a legally precarious line of work with limited protection.

What is important to note from the above studies is that few, if any, were based on official statistics released by police or justice departments. Rather, these numbers were gathered by interest groups or researchers who focused on violence against specific groups, such as human rights groups, trans rights groups, sex worker support groups, and so on. Because of the block-identification of the category of 'women' in VAW, official statistics on GBV are typically not disaggregated by gender orientation or identity (Wells and Polders, 2006; UN OHCHR, n.d.), or by the numerous other identities that may increase a person's risk of experiencing GBV. Thus, there are limited records kept of whether a survivor is cis-het, lesbian, trans, a sex worker, disabled, or a refugee. This then limits the capacity for research to be done on how, when, and to what degree these different groups experience violence. While acknowledging that all women face the potential risk of GBV, this risk is by no means equally shared amongst women, and focusing on violence against women as a unitary or homogenous group risks oversimplifying the issue. It is not simply a matter of men exerting power over women, a power which patriarchal

\footnotetext{
${ }^{5}$ CEDAW General Recommendation No. 35 lists the following aspects which can increase a women's risk of GBV: ethnicity/race, indigenous or minority status, colour, socioeconomic status, caste, language, religion, belief, political opinion, national origin, marital status, maternity, parental status, age, urban or rural location, health status, disability, property ownership, being lesbian, bisexual, transgender or intersex, illiteracy, seeking asylum, being a refugee, internally displaced or stateless, widowhood, migration status, heading households, living with HIV/AIDS, being deprived of liberty, and being in prostitution, as well as trafficking in women, situations of armed conflict, geographical remoteness and the stigmatization of women who fight for their rights, including human rights defenders (2017: 4-5).
} 
societies and misogynistic norms have enabled, but a much more nuanced situation involving multiple intersecting identities at all times.

\section{LGB}

Related to the problem of presenting all women as a homogenous group, is the GBV that those in the LGB community face. They may often be excluded from understandings and applications of GBV, despite the very obvious gendered basis of the violence. For example, an issue which is particularly widespread in South Africa is that of homophobic rape. ${ }^{6}$ Lesbian women, and particularly Black lesbian women who are more masculinepresenting or 'butch', are raped with the stated intention of altering their sexual orientation, or 'turning them straight'. This is an issue which is worryingly prevalent in South Africa, and was the subject of a Human Rights Watch report, titled We'll Show You You're a Woman (Nath, 2011). In these instances, 'Black lesbians in South Africa are raped, tortured and murdered because they refuse to conform to dominant heterosexual, patriarchal norms and values' (Maotoana et al., 2019: 13939). These women are raped because they are women, and because they are Black, and because they are not presenting 'correctly' as women because they are not heterosexual or because they dress in traditionally masculine clothing. Their sexual orientation therefore puts them at higher risk of GBV than if they were heterosexual, while their identity as Black women puts them at higher risk than if they were white.

As a further example, in a review of research on IPV and sexual abuse against LGBTQIA+ people in the USA, Brown and Herman reported that bisexual women were 'more than twice as likely to have experienced severe physical violence by an intimate partner than women in the general population' (2015: 9), but that '89.5\% of bisexual women reported only male perpetrators of intimate partner violence, rape, and/or stalking' (2015: 11). Thus, bisexual women were at higher risk of IPV, but almost exclusively from their male partners, suggesting that not only are they experiencing 'normal' IPV, but that their perceived deviance from the norm of heterosexuality may trigger higher levels of violence than 'just' being a woman in an intimate relationship with a man.

Along with this, if the only focus in GBV prevention and support interventions is on male VAW, then IPV within queer relationships, or same-sex sexual violence, such as between two women or two men, will not be included. These forms of violence tend to get little attention. For example, IPV within lesbian relationships is heavily under-researched, with little recognition of it as an issue (Tallis et al., 2020). However, in a study of existing research on IPV against LGBT people, Brown and Herman found that lesbians had as high or higher life prevalence of IPV than the general US population (2015: 21). However, worryingly, women who had experienced same-sex IPV sometimes did not initially consider it to be IPV, citing beliefs that 'only men perpetrate violence and that what violent acts women do commit are not serious or as dangerous as those perpetrated by men' (2015: 17). Thus, the dominant understanding of GBV may deter survivors from seeking help because they do not believe that they 'qualify'.

Along with this, even in countries which recognise and legalise same-sex relationships, there may still be substantial stigma or violence aimed at these communities, such that survivors of same-sex violence may be reluctant to report it (Brown and Herman, 2015). For example, even though South Africa provides full recognition and legalisation of same-sex relationships, marriages, and adoption, in practice the LGBTQIA+ community still faces extreme levels of violence. Thus, as Crehan and McCleary-Sills (2015: 4) found, lesbian, bisexual and trans women 'can experience great difficulty in accessing justice or legal redress (...) many fear their report will not be taken seriously or the police will further abuse them'.

\section{TIQA+}

In a similar manner, the application of a narrow framing of GBV as meaning only violence against cis-het women risks excluding those who are gender non-confirming (GNC) or otherwise part of the TIQA+ community. Many definitions of GBV (e.g., UN OHCHR, n.d.; IASC, 2015; CVC and UNWomen, 2016) specifically note that this violence is perpetrated because of the survivor's gender or their non-compliance with perceived gender norms, and it is therefore hard to understand any form of violence against trans folk as being anything but gender-based. However, many countries are slow to recognise a person's gender identity (if they are willing to recognise trans identities at all), meaning that a trans person may be misgendered in police and media reports, and crime statistics. For example, while South Africa's laws allow a person to apply to alter their sex description on their identification documents (The Alteration of Sex Description and Sex Status Act of 2003), it requires them to have undergone or be undergoing gender reassignment, either surgically or hormonally, and the waiting period is reported to be anything from one to seven years (Deyi et al., 2015). Thus, it may take many years for a person's legal documents to reflect their gender, if they meet the criteria to change it at all. This means that violence against a trans woman

\footnotetext{
${ }^{6}$ While this is often termed 'corrective rape', this is a problematic framing of the crime, implying some form of 'correction' of someone's (incorrect) sexual orientation. The idea of sexual orientation as in need of 'correction' is inherently violent in itself. I therefore use the term 'homophobic rape', to specifically highlight the homophobia underlying the act (Anguita, 2012), and to remove any perceived justification for it.
} 
may not be included in police reports and crime statistics as a case of GBV, because they may be misgendered as male, and therefore not be included in an understanding of violence against women. Yet this ignores the fact that much violence against trans women is perpetrated specifically because they do not meet societal gender norms and expectations, and should therefore be included in understandings and statistics of GBV.

While the fact of this exclusion from understandings of GBV is jarring enough, the extremely high rates of violence that trans women in particular experience makes it a cause for even greater concern. Across all intersecting identities, trans women are reported to experience higher rates of violence than almost any other group, no matter their racial/ethnic, religious, socioeconomic, or citizenship status (UN OHCHR, n.d.; Brown and Herman, 2015; Margalit, 2018; Rao et al., 2019). Findings from the 2015 US Transgender Survey (James et al., 2016) found that trans respondents experienced higher rates of almost every type of GBV. For example, 35\% of respondents had experienced physical IPV (compared to $30 \%$ of the US adult population), while $24 \%$ had experienced severe physical IPV (compared to 18\% of the US adult population) (2016: 198). Along with this, trans respondents' intersecting identities further increased their risk of violence. Trans respondents who had participated in sex work, who had experienced homelessness, or who had disabilities were more likely to have been sexually assaulted in their lifetime than respondents who did not have those identities (2016: 205). In a similar finding, Goldberg, Jadwin-Cakmak and Harper (2018: 22) noted that trans and GNC youth who had participated in sex work were much more likely to have experienced IPV than those who had not participated in sex work. Thus, trans folk experience a higher risk of all forms of gendered violence, as 'their societally unprivileged statuses attract violence not based on relationship issues, but rather social issues of racism, transphobia, [and] cultural gender roles' (Clark et al., 2017: 1-2).

\section{Men}

The final concern is that narrow framings of GBV exclude violence against and between men. As an important caveat, the author acknowledges that there is significant discomfort with the notion of including violence against (cis-het) men in understandings of GBV. While men undoubtedly experience extremely high rates of violence, as will be outlined below, this article is not implying that this violence is predominantly being perpetrated by women, those in the LGBTQIA+ community, or any other marginalised groups. Throughout all the statistics that will be discussed below, it is important to note that the vast majority of violence is perpetrated by men. The problem overwhelmingly remains men's use of violence. Similarly, this article does not argue for a shift in focus away from groups who are substantially more marginalised in society than cis-het men. However, this article does argue that violence between men (and the more-limited cases of violence against men by women) is strongly gendered, and in large part arises due to patriarchal and misogynistic expectations around men's use and experience of violence. In more practical terms, if those who perpetrate one form of violence are more likely to perpetrate others (Fleming et al., 2015: 251), there is also the risk that problematising only one form of gendered violence may at best result in very limited reductions in any form of violence. Thus, including violence between men in understandings of gendered violence may prove to be beneficial in preventing gender-based violence and gender inequality more broadly.

Given the societal expectation of violence in many versions of masculinities, or their contextual gender norms, arguably most forms of violence perpetrated by men are gendered to some extent. As Fleming et al. note, 'men's violence is not simply about dominance over women but can also be viewed as establishing hierarchies among men (...) [and] most violence perpetration by men has at its roots norms of masculinities' $(2015: 251,253)$. Thus, 'fighting between males for dominance is the most likely reason why males, more than females, die from violence' (Ratele, 2010: 21). It is important to note that not all masculinities will require violence, and that these masculinities are fluid and changeable, rather than static. Despite this, research has highlighted 'a physicality and violence in performances of hegemonic masculinities' (Shefer et al., 2015, s99). Similarly, a wide range of literature has highlighted how sexual and physical violence, aggression, and coercion are bound up with dominant ideas of what it is to be a man across diverse South African communities (see for example, Jewkes et al., 2009; Jewkes and Morrell, 2010; GenderLinks and MRC, 2012). Thus, while not all masculinities require violence, the extremely high levels of violence perpetrated by men in South Africa arguably suggest at least a lack of disapproval, and at most an active expectation, of violence from men. Men's use and experience of violence is therefore heavily gendered.

For example, it is almost exclusively men who are expected or conscripted to join armies and armed groups, ensuring that it is men who face militarised violence, while women and children are typically grouped together as 'innocents' or 'collateral damage' (Jones, 2000). The enforced link between masculinity and militarisation has been well-documented (e.g., Cock, 1991; Farr, 2002; Langa and Eagle, 2008; Cockburn, 2010; UN-IAWG, 2012), ${ }^{7}$ upholding the damaging heteronormative assumption that men are inherently violent, resulting in men and boys being sent to war and traumatised or killed because of their supposedly inherent violence, embodying their assumed

\footnotetext{
${ }^{7}$ There is a significant body of literature which looks at further systems of collective, institutional and organised violence,
} which is beyond the scope of this paper. For more, see Elias and Rai, 2019; Hearn et al., 2020. 
gender role. Framing this violence as inherent or biologically based may result in limited efforts to address it or reduce it. As Dolan asks (2014: 492-3),

why do we still fail to see that the militarization of men is an egregious form of GBV (...) not only because the products of militarization are highly represented among perpetrators of sexual violence (...) but also because in the course of becoming and being militarized, men themselves are victims of lethal doses of GBV.

In a related matter, while women undoubtedly experience certain forms of violence at extremely high rates, men experience other forms of violence, such as murder, at significantly higher rates than women. For example, $81 \%$ of homicide victims globally are male (UNODC, 2019), and according to Indexmundi (2019), South African men had one of the highest mortality rates in the world in 2017 (378.91/1000 male adults). Along with this, the WHO (2015) found that men in South Africa are almost five times as likely to be murdered as women (43.4/100 000 for men versus 9.6/100 000 for women). Studies conducted within South Africa have found similarly high rates of male homicide victimisation. For example, Swart, Seedat and Nel (2015) found that $81 \%$ of adolescent homicide victims in Johannesburg were male; while Ratele (2010: 20) found that urban young black men (aged 20 to 40) were up to nine times as likely to die from homicidal violence as black females in the same age group.

Along with this, although women and girls experience higher rates of sexual violence, men and boys do also experience sexual violence, at the hands of both women and other men (Fleming et al., 2015: 250; Nyoni and Warive, 2017; Kiss et al., 2020). However, the stigma against men who experience such violence is strong, due to the perceived shame and 'feminisation' of being a male survivor of sexual violence, meaning that reporting rates among men may be even lower than those of women (Margalit, 2018; Kiss et al., 2020). This shame highlights the extremely gendered nature of the crime, and the way in which, when it is perpetrated against men, it is also specifically because of their societal gender roles. Thus, as Fleming et al. point out (2015: 493),

By concentrating on females' subordinate status rather than the subordinate status of the feminine, it thus misses the vulnerabilities of gender non-conforming men (...) and limits itself to systematically reproduced gender inequality manifest within a (heterosexual) male-female binary. It also misses the vulnerability to violence of normative men in that it assumes that it is subordinate status in society that creates vulnerability to violence, and fails to see that the inverse logic can and does hold true. Higher social status can render men's subordination through sexual violence strategic.

Thus, excluding any form of violence against men from the applied understanding of GBV is problematic for a number of reasons. The first is that it excludes the fact that violence against gay, bisexual, GNC or trans men is extremely gendered, as it punishes them for deviating from the heterosexual 'norm'. The second is that it assumes that any form of violence against (cis-het) men is 'just' violence, rather than gender-based violence, and is simply an inherent fact, rather than something that can be researched or problematised or addressed. This may therefore limit the effectiveness of interventions which are attempting to prevent GBV through working with men. Thus, work on masculinities urgently needs to include a focus on violence between men.

\section{CONCLUSION}

GBV remains a serious concern globally, with few signs that it is abating. This suggests a need to find new ways to conceptualise and address the issue in order to reduce the rates of such violence. This article argues that a key way to do so is by broadening the applied definition of GBV, by expanding it beyond its current traditional focus on men's violence against women. There is no doubt that VAW is a serious issue around the world, as well as in South Africa, requiring attention and effort to be addressed. However, current interventions have had limited success in this regard, and this may be partly due to the narrow focus on VAW in GBV work. By not addressing heteropatriarchal gender norms, and not troubling gender binarisms, this narrow focus may ultimately prove ineffective in preventing violence.

As a first concern, focusing solely on violence against women risks implying that women are a unitary and homogenous group, all facing equal risk of and exposure to violence. However, as has been highlighted throughout this article, women face hugely varied levels of violence, depending on their intersecting identities. Trans women, disabled women, queer women, women of colour, and sex workers, among others, are at significantly higher risk of violence. Acknowledging and highlighting this, in research and in statistics collected about GBV, as well as pedagogical, policy and practical interventions, will enable policymakers, legal systems, and support groups to tailor responses to better address the needs of these marginalised groups.

Along with this, the heteronormative focus on male violence against females may result in the exclusion of violence against those in the LGBTQIA+ community. Official definitions of GBV often specifically highlight 
violence against a person because of their gender role or non-conformity with gender norms; thus, violence against those in the LGBTQIA+ community will arguably almost always be gendered. However, the focus on VAW may exclude same-sex violence, violence against GBTQIA+ men, and violence against trans women, who may be misgendered as men in countries which are slow or unwilling to recognise their gender. This may be especially true of GBV support interventions, which are typically geared to respond primarily to female survivors of male violence, meaning that they may be ill-suited to anyone who does not fall into this category. Restrictive legal contexts, which have a narrow definition of sexual violence, which criminalise same-sex relationships and sex, or which refuse to recognise transgender persons will likely exacerbate this issue.

Finally, restrictive understandings of GBV will likely exclude violence against and between men. As noted above, while including violence against cis-het men in definitions of GBV is often contentious, this article argues that, when viewed through the lens of the societal expectations underlying masculinities, much of the violence perpetrated both by and against men is gendered. As noted above, men who do not conform to heteronormative gender roles, such as GBTQIA+ men, may be at high risk for GBV. Similarly, violence used against men often has the intention of emasculating, shaming or 'feminising' them, specifically because of the societal norms and gendered expectations arising in patriarchal societies. Along with this, if interventions to address and prevent GBV do not focus on men's use of violence more broadly (including violence between men), then their effectiveness in addressing GBV will arguably be limited. This article therefore argues for the use of broader, more inclusive understandings of GBV in practice, which will hopefully be of use in improving interventions to address and prevent such violence in the future.

\section{ACKNOWLEDGEMENT}

The author is currently a post-doctoral fellow in the Women's and Gender Studies Department, Faculty of Arts, University of the Western Cape, with funding from the Andrew W. Mellon Foundation-funded project, New imaginaries for an intersectional critical humanities project on gender and sexual justice (Grant no: G31700714).

\section{REFERENCES}

Alteration of Sex Description and Sex Status Act, No 49 of 2003.

Anderson, M. J. (1999/2000). Rape in South Africa. Georgetown Journal of Gender and Law, 1(3), 789-821.

Anguita, L. A. (2012). Tackling Corrective Rape in South Africa: The Engagement Between the LGBT CSOs and the NHRIs (CGE and SAHRC) and its Role. The International Journal of Human Rights, 16(3), 489-516. https://doi.org/10.1080/13642987.2011.575054

Aosved, A. C. and Long, P. J. (2006). Co-Occurrence of Rape Myth Acceptance, Sexism, Racism, Homophobia, Ageism, Classism, and Religious Intolerance. Sex Roles, 55, 481-492. https://doi.org/10.1007/s11199-0069101-4

Bhandari, N. (2008). Documentation of a Campaign to End Violence Against Women and Girls and to Promote Gender Equality in India - MASV AW. Uttar Pradesh, India: Save the Children, MASVAW.

Breckenridge, K. (1998). The Allure of Violence: Men, Race and Masculinity on the South African Goldmines, 1900-1950. Journal of Southern African Studies, 24(4), 669-693. https://doi.org/10.1080/03057079808708596

Brown, T. N. T. and Herman, J. L. (2015). Intimate Partner Violence and Sexual Abuse Among LGBT People - A review of existing research. The Williams Institute: Los Angeles.

Caribbean Vulnerable Communities Coalition (CVC), UN Women. (2016). Belize: Gender based violence (GBV) and sexually transmitted infections (STIs), including the buman immunodeficiency virus/acquired immunodeficiency syndrome. Population specific information for women, girls, lesbian, bisexual and transgender women, sex workers and other women affected by gender based violence. Kingston, Jamaica: CVC.

CEDAW. (1992). General Recommendation No. 19: Violence Against Women. CEDAW A/47/38.

CEDAW. (2017). General Recommendation No. 35 on Gender-Based Violence Against Women, Updating General Recommendation No. 19. CEDAW/C/GC/35.

Christofides, N. J., Hatcher, A. M., Rebombo, D., McBride, R.-S., Munshi, S., Pino, A., Abdelatif, N., ... Jewkes, R. K. (2020). Effectiveness of a Multi-Level Intervention to Reduce Men's Perpetration of Intimate Partner Violence: A Cluster Randomised Controlled Trial. Trials, 21, 359. https://doi.org/10.1186/s13063-020-04386z

Clark, K. A., Mays, V. M., and Cochran, S. D. (2017). Extreme Violence and the Invisibility of Women Who Murder: The Intersectionality of Gender, Race, Ethnicity, Sexual Orientation, and Gender Identity Equals Silence. Violence and Gender, 4(4), 117-120. https://doi.org/10.1089/vio.2017.0036 
Cock, J. (1991). Colonels \& Cadres: War and gender in South Africa. Cape Town: Oxford University Press.

Cockburn, C. (2010). Gender Relations as Causal in Militarization and War. International Feminist Journal of Politics, 12(2), 139-157. https://doi.org/10.1080/14616741003665169

Crehan, P. and McCleary-Sills, J. (2015). Violence Against Women and Girls (VAWG) Resource Guide - Brief on violence against sexual and gender minority women. World Bank, Global Women's Institute, IDB, ICRW.

Criminal Law (Sexual Offences and Related Matters) Amendment Act, No 32 of 2007.

Deyi, B., Kheswa, S., Theron, L., Mudarikwa, M., May, C. and Rubin, M. (2015). Briefing Paper: Alteration of Sex Description and Sex Status Act, No. 49 of 2003. Cape Town (South Africa): LRC/Gender Dynamix.

Dolan, C. (2014). Letting Go of the Gender Binary: Charting New Pathways for Humanitarian Interventions on Gender-Based Violence. International Review of the Red Cross, 96(894), 485-501. https://doi.org/10.1017/S1816383115000120

Domestic Violence Act, No 116 of 1998.

Dunkle, K., van der Heijden, I., Stern, E. and Chirwa, E. (2018). Disability and Violence Against Women and Girls. What Works to Prevent Violence. UK: UK Aid.

Elias, J. and Rai, S. M. (2018). Feminist Everyday Political Economy: Space, Time, and Violence. Review of International Studies, 45(2), 201-220. https:/ / doi.org/10.1017/S0260210518000323

Ellsberg, M., Arango, D. J., Morton, M., Gennari, F., Kiplesund, S., Contreras, M. and Watts, C. (2015). Prevention of Violence Against Women and Girls: What Does The Evidence Say? The Lancet, 385(April 18), 1555-1566. https:// doi.org/10.1016/S0140-6736(14)61703-7

European Institute for Gender Equality (EIGE) (n.d.). What Is Gender-Based Violence? https:/ / eige.europa.eu/gender-based-violence/what-is-gender-based-violence. (Accessed 2 April 2020).

Evens, E., Lanham, M., Santi, K., Cooke, J., Ridgeway, K., Morales, G., Parker, C., ..., Dayton, R. (2019). Experiences of Gender-Based Violence Among Female Sex Workers, Men Who Have Sex with Men, and Transgender Women in Latin America and the Caribbean: A Qualitative Study to Inform HIV Programming. BMC International Health and Human Rights, 19(9), 9. https:/ / doi.org/10.1186/s12914-019-0187-5

Farr, V. (2002). Gendering Demilitarization as a Peacebuilding Tool. Bonn: Bonn International Center for Conversion.

Fleming, P. J., Gruskin, S., Roko, F. and Dworkin, S. L. (2015). Men's Violence Against Women and Men are Inter-Related: Recommendations for Simultaneous Intervention. Social Science and Medicine, 146, 249-256. https://doi.org/10.1016/j.socscimed.2015.10.021

Flintoff, R. (2001). Sexual Assault, in J. Nicoletti, S. Spencer-Thomas, C.M. Bollinger (eds), Violence Goes to College: The authoritative guide to prevention and intervention 2nd ed. Illinois: Charles C. Thomas.

GenderLinks and Medical Research Council. (2012).TheWar@ Home: Findings of the Gender Based Violence Prevalence Study in Gauteng, Western Cape, KwaZulu Natal and Limpopo Provinces of South Africa. Gauteng: GenderLinks, MRC.

Gibbs, A., Myrttinen, H., Washington, L., Sikweyiya, Y. and Jewkes, R. (2020). Constructing, Reproducing and Challenging Masculinities in a Participatory Intervention in Urban Informal Settlements in South Africa. Culture, Health \& Sexuality, 22(5), 535-550. https:// doi.org/10.1080/13691058.2019.1614671

Goldberg, T., Jadwin-Cakmak, L. and Harper, G. W. (2018). Intimate Partner Violence Among Transgender Youth: Associations with Intrapersonal and Structural Factors. Violence and Gender, 5(1), 19-25. https://doi.org/10.1089/vio.2017.0041

Gqola, P. D. (2015). Rape: A South African nightmare. Johannesburg: MFBooks Joburg.

Graaff, K. and Heinecken, L. (2017). Masculinities and Gender-Based Violence in South Africa: A Study of a Masculinities-Focused Intervention Programme. Development Southern Africa, 34(5), 622-634. https://doi.org/10.1080/0376835X.2017.1334537

Hamber, B. (2000). 'Have No Doubt it is Fear in the Land': An Exploration of the Continuing Cycles of Violence in South Africa. Southern African Journal of Child and Adolescent Mental Health, 12(1), 5-18. https://doi.org/10.1080/16826108.2000.9632364

Hearn, J., Strid, S., Humbert, A. L., Balkmar, D. and Delaunay, M. (2020). From Gender Regimes to Violence Regimes: Re-Thinking the Position of Violence. Social Politics, Summer: 1-24. https://doi.org/10.1093/sp/jxaa022

Indexmundi. (2019). Mortality Rate, Adult Male. https://www.indexmundi.com/facts/indicators/SP.DYN.AMRT .MA/rankings, (Accessed 12 November 2020).

Inter-Agency Standing Committee (IASC). (2015). Guidelines for Integrating Gender-Based Violence Interventions in Humanitarian Action: Reducing risk, promoting resilience and aiding recovery. https://gbvguidelines.org/en/. (Accessed 12 November 2020).

Interim GBVF Steering Committee. (2019). Draft National Gender-Based Violence \& Femicide Strategic Plan 2020 2030. https://www.gov.za/site/default/files/gcis_document/21909/nspongbvfdraft.pdf. (Accessed 12 February 2021). 
James, S. E., Herman, J. L., Rankin, S., Keisling, M., Mottet, L. and Anafi, M. (2016). The Report of the 2015 US Transgender Survey. Washington DC: National Center for Transgender Equality.

Jewkes, R. and Morrell, R. (2010). Gender and Sexuality: Emerging Perspectives from the Heterosexual Epidemic in South Africa and Implications for HIV Risk and Prevention. Journal of the International AIDS Society, 13(6), 111. https://doi.org/10.1186/1758-2652-13-6

Jewkes, R., Flood, M. and Lang, J. (2015). From Work with Men and Boys to Changes of Social Norms and Reduction of Inequities in Gender Relations: A Conceptual Shift in Prevention of Violence Against Women and Girls. The Lancet, 385(April 18), 1580-1589. https://doi.org/10.1016/S0140-6736(14)61683-4

Jewkes, R., Sikweyiya, Y., Morrell, R. and Dunkle, K. (2009). Understanding Men's Health and Use of Violence: Interface of rape and HIV in South Africa. Pretoria: MRC.

Jones, A. (2000). Gendercide and Genocide. Journal of Genocide Research, 2(2), 185-211. https://doi.org/10.1080/713677599

Kiss, L., Quinlan-Davidson, M., Pasquero, L., Ollé Tejero, P., Hogg, C., Theis, J., Park, A., Zimmerman, C. and Hossain, M. (2020). Male and LGBT Survivors of Sexual Violence in Conflict Situations: A Realist Review of Health Interventions in Low- And Middle-Income Countries. Conflict and Health, 14, 11. https://doi.org/10.1186/s13031-020-0254-5

Langa, M. and Eagle, G. (2008). The Intractability of Militarised Masculinity: A Case Study of Former Self-Defence Unit Members in the Kathorus Area, South Africa. South African Journal of Psychology, 38(1), 152-175. https://doi.org/10.1177/008124630803800109

Maotoana, M., Govender, S. and Nel, K. (2019). The Experiences of Black Lesbians in a South African Township. Gender \& Behavior, 17(4), 13936-13947.

Margalit, A. (2018). Still a Blind Spot: The Protection of LGBT Persons During Armed Conflict and Other Situations of Violence. International Review of the Red Cross, 100(1-2-3), 237-265. https://doi.org/10.1017/S1816383119000201

Mathews, S., Abrahams, N., Martin, L. J., Vetten, L., van der Merwe, L. and Jewkes, R. (2004). 'Every Six Hours a Woman is Killed by Her Intimate Partner': A National Study of Female Homicide in South Africa. MRC Policy Brief, 5. Cape Town: Medical Research Council of South Africa.

Morrell, R. (1998). Of Boys and Men: Masculinity and Gender in Southern African Studies. Journal of Southern African Studies, 24(4), 605-630. https://doi.org/10.1080/03057079808708593

Morrell, R., Jewkes, R. and Lindegger, G. (2012). Hegemonic Masculinity/Masculinities in South Africa: Culture, Power and Gender Politics. Men and Masculinities, 15(1), 11. https://doi.org/10.1177/1097184X12438001

Naidu, E. and Mkhize, N. (2005). Gender-Based Violence: The Lesbian and Gay Experience. Agenda: Empowering women for gender equity, 19(66), 34-38.

Nath, D. (2011). 'We'll Show You You're A Woman': Violence and discrimination against black lesbians and transgender men in South Africa. South Africa: Human Rights Watch.

Nyoni, P. and Warive, E. (2017). Impact of Conceptualization of Gender Based Violence Policies on Achieving Health Equity in Low and Middle Income Countries. Conference presentation at New Voices in Global Health: Protecting the Most Vulnerable. 27-34.

Pulerwitz, J., Barker, G. and Segundo, M. (2004). Promoting Healthy Relationships and HIV/STI Prevention for Young Men: Positive findings from an intervention study in Brazil. Washington DC: USAID.

Rao, S., Tchoumke Pangroup, A., Dakota, R. J., Ross-Reed, D. and Forster-Cox, S. (2019). Violence in Lesbian, Gay, Bisexual, Transgender, and Queer Communities: Preliminary Findings from New Mexico. Violence and Gender, 6(4), 235-237. https://doi.org/10.1089/vio.2019.0036

Ratele, K. (2010). Watch Your Man. Young Black Males at Risk of Homicidal Violence. SA Crime Quarterly, 33(September), 19-24. https:// doi.org/10.17159/2413-3108/2010/v0i33a881

Shefer, T., Kruger, L.-M. and Schepers, Y. (2015). Masculinity, Sexuality and Vulnerability in 'Working' with Young Men in South African Contexts: 'You Feel like a Fool and an Idiot... a Loser'. Culture, Health \& Sexuality, 17(sup2), 96-111. https:// doi.org/10.1080/13691058.2015.1075253

Sonke Gender Justice. (n.d.). Stop Gender Violence: A national campaign. https://genderjustice.org.za/project/policydevelopment-advocacy/stop-gender-violence-national-campaign/. (Accessed 9 February 2021).

Stop Gender Violence Campaign. (2017). Policy Brief: Call for a national strategic plan on gender-based violence shadow framework. https://genderjustice.org.za/publication/call-national-strategic-plan-gender-based-violenceshadow-framework/. (Accessed 9 February 2021).

Swart, L.-A., Seedat, M. and Nel, J. (2015). The Situational Context of Adolescent Homicide Victimization in Johannesburg, South Africa. Journal of Interpersonal Violence, 1-25 (e-pub). https://doi.org/10.1177/ 0886260515613342

Tallis, V., Jean-Pierre, T. and Madi, T. (2019). When the Personal Remains Personal. Intimate Partner Violence in Lesbian Relationships. Agenda (2019), 1-7. DOI: 10.1080/10130950.2019.1706988. 
Thompson, M. (2000). Life after Rape: A Chance to Speak? Sexual and Relationship Therapy, 15(4), 325-343. https://doi.org/10.1080/713697439

Traves-Kagan, S., Maman, S., Khoza, N., MacPhail, C., Peacock, D., Twine, R., ... Pettifor, A. (2020). Fostering Gender Equality and Alternatives to Violence: Perspectives on a Gender-Transformative Community Mobilisation Programme in Rural South Africa. Culture, Health \& Sexuality, 22(sup1), 127-144. https://doi.org/10.1080/13691058.2019.1650397.

UN Office for High Commissioner on Human Rights (OHCHR). (N.d.). Fact Sheet: Homophobic and transphobic violence. $\quad$ https://www.ohchr.org/Documents/Issues/Discrimination/LGBT/FactSheets/unfe-27UN_Fact_Sheets_Homophobic_English.pdf. (Accessed 03 April 2020).

UN-IAWG. (2012). Blame it on the War? The gender dimensions of violence in disarmament, demobilization and reintegrationreport and recommendations for action. Geneva: UN-IAWG.

UNODC. (2019). Global Study on Homicide 2019, Booklet 2. UNODC: Vienna.

UNODC. (n.d.). Sexual Violence. https://dataunodc.un.org/data/crime/sexual-violence. (Accessed 07 October 2020).

UNWomen. (2013). Terminology and Definitions. https://www.endvawnow.org/en/articles/1474-terminology-anddefinitions.html. (Accessed 12 November 2020).

Viitanen, A. P. and Colvin, C. J. (2015). Lessons Learned: Program Messaging in Gender-Transformative Work with Men and Boys in South Africa. Global Health Action, 8, 27860. https://doi.org/10.3402/gha.v8.27860

Wells, H. and Polders, L. (2006). Anti-Gay Hate Crimes in South Africa: Prevalence, Reporting Practices, and Experiences of the Police. Agenda: Empowering Women for Gender Equity, 20(67), 20-28.

WHO. (2015). Violence Info: South Africa. https://apps.who.int/violence-info/country/ZA. (Accessed 12 November 2020).

World Health Organisation (WHO). (2013). Responding to Intimate Partner Violence and Sexual Violence Against Women - WHO clinical and policy guidelines. Geneva: WHO.

Citation: Graaff, K. (2021). The Implications of a Narrow Understanding of Gender-Based Violence. Feminist Encounters: A Journal of Critical Studies in Culture and Politics, 5(1), 12. https://doi.org/10.20897/femenc/9749

Copyright (C) 2021 by Author/s and Licensed by Lectito BV, Netherlands. This is an open access article distributed under the Creative Commons Attribution License which permits unrestricted use, distribution, and reproduction in any medium, provided the original work is properly cited. 